\title{
REPORT ON \\ POLICY AND ACTIVITIES \\ CONCERNING PUBLIC AWARENESS \\ OF HEALTH EFFECTS OF LOW-LEVEL RADIATION
}

\section{Prepared for \\ Committee on \\ Interagency Radiation Research and Policy Coordination}

By

Modern Communications

Washington, DC

November 1986

MASTER 


\title{
POLICY AND ACTIVITIES CONCERNING PUBLIC AWARENESS \\ OF HEALTH EFFECTS OF LOW-LEVEL RADIATION
}

\author{
Prepared for \\ Committee on Interagency Radiation Research \\ and Policy Coordination
}

\section{DISCLAIMER}

This report was prepared as an account of work sponsored by an agency of the United States Government. Neither the United States Government nor any agency thereof, nor any of their employees, makes any warranty, express or implied, or assumes any legal liability or responsibility for the accuracy, completeness, or usefulness of any information, apparatus, product, or process disclosed, or represents that its use would not infringe privately owned rights. Reference herein to any specific commercial product, process, or service by trade name, trademark, manufacturer, or otherwise does not necessarily constitute or imply its endorsement, recommendation, or favoring by the United States Government or any agency thereof. The views and opinions of authors expressed herein do not necessarily state or reflect those of the United States Government or any agency thereof.

By

Modern Communications

Washington, D.C.

November 1986 


\section{TABLE OF CONTENTS}

Executive Summary and Conclusions i

Introduction 1

Methodology 2

Discussion of Interview Findings 4

Department of Energy 4

Department of Interior 6

Federal Emergency Management Agency 7

Literature Acquisition and Review 9

$\begin{array}{ll}\text { Summary } & 20\end{array}$

$\begin{array}{ll}\text { Footnotes } & 21\end{array}$

$\begin{array}{ll}\text { Appendices } & 22\end{array}$

Appendix A - Interview Guidelines A

Appendix B - Interview Candidates B

Department of Energy B-i

Department of Interior B-ii

Federal Emergency Management Agency B-iii

Appendix C

FEMA Newsletter

C

c-i 


\section{EXECUTIVE SUMMARY AND CONCLUSIONS}

One of the issues which emerged from the Committee on Interagency Radiation Research \& Policy Coordination's (CIRRPC) Executive Committee's meetings with senior staff and member agencies in 1985 was the inadequacy of communications and interactions between federal agencies, the scientific community, the public and the various segments of the media on ionizing and non-ionizing radiation.

In the summer of 1986 , the Executive Committee authorized a study limited to determining policy and practices relevant to dissemination of information to the public on radiation health effects in three federal agencies. This report summarizes findings on two broad questions related to the communication issue: What, if any, are the policies under which federal agencies operate in disseminating information on health effects of radiation and what are the current programs and activities designed to provide the public information on health effects of radiation.

CIRRPC selected three agencies: the Department of Energy (DOE), Department of Interior (DOI), and the Federal Emergency Management Agency (FEMA) to participate in a study to acquire facts relating to policies and practices relevant to information dissemination on radiation health effects. After consultation with the agencies, CIRRPC provided lists of recommended interview candidates to the contractor. Individuals were selected on the basis of their positions with relevant program areas or their responsibility for public information in the subject agencies.

The contractor developed guidelines for interviews, which were reviewed and approved by CIRRPC prior to the conduct of any interviews. These guidelines provide the focus for the interviews. Specifically, they address the evolution of policy, its articulation and perception by various program staff, and staff's perception of its adequacy. They also address the perceived need for activities, descriptions of current activity, and staff perceptions of the need for additional activities. These guidelines were used in interviews with twenty-three individuals in the three subject agencies.

Concurrent with the conduct of interviews, the contractor requested from public affairs and publications offices of the three agencies information on radiation health effects. Three people called each of the agencies to request information. The interviewer purposely did not request printed information, but accepted the unsolicited publications offered by the interviewees. 


\section{Conclusions}

On the basis of interviews conducted and literature reviewed, we have drawn tentative conclusions regarding the existence of policies affecting dissemination of information on health effects of low-level radiation. We have also examined practices in the agencies related to this issue and have characterized them briefly. We refer to the conclusions as tentative because our study of three agencies cannot be extrapolated to represent a statement about an overall federal policy.

There are two summarizing statements we can make about policy:

- There is no single, coherent policy regarding public awareness of health effects for any of the three agencies.

- There is not a consistent statement of the need for programs and policies regarding this issue.

There are no two or three statements to which we can point to explain the absence of policy nor the absence of any consistent perception of the need for a policy. There are, however, several observations that might help explain these two findings.

First of all, the agencies, on a whole, do not consider themselves to be the primary agent for dissemination of information on radiation health effects to the public. Program people in Nuclear Energy at DOE described the agency as having a policy of keeping the public informed, but that statement is not supported by reports from the Office of Public Affairs, nor the response to inquiries for information. Every one of the three agencies, when asked to provide literature on the topic, referred callers first to other agencies. Only after repeated requests were callers referred to program areas where they could obtain relevant information. The agencies to which callers were most commonly referred were the Environmental Protection Agency (EPA) and the Department of Health and Human Services (HHS), though one caller was referred to the Department of Labor (DOL).

Secondly, as several interviewees at DOE and several of the publications point out, there is disagreement within the scientific community as to the definition of low-level radiation and to its health effects.

A third factor that might bear on the absence of specific policies pertaining to radiation health effects is the question of whether there is a need for a specific policy or policies. Each agency has the authority to release information on its program activities; perhaps this is perceived as sufficient by the agencies. 
A fourth factor which might impact the absence of a policy is the lack of communication within agencies to clarify the various departments' perceptions of policy and program needs in this area.

The activities of the agencies that relate directly to public information on radiation health effects is reactive. The only aggressive attempts to educate the public about low-level radiation health effects were part of the Public Information Plan of the DOE Uranium Mill Tailings Project. The plan calls for information dissemination on health effects, but it is unclear what information was actually developed and disseminated as a consequence of the plan. The reactive programs generally consist of providing literature in response to inquiries, but callers discovered that agencies do not have established procedures for making such materials available.

The greatest strength of the agencies in supplying information on health effects of radiation appears to be in special courses. FEMA offers a variety of courses on emergency situations, some of whch contain information on radiation health effects. The Department of Labor has quite a lot of information on radiation health effects in training manuals for radiographers. The Department of Energy has one information pamphlet, "Understanding Radiation," which describes health effects, but it is not readily available.

We could discover no other means of information dissemination to the public.

There are no recent publications on radiation health effects; therefore we could not assess the review procedures for such publications. We did perceive, however, from our interviews and literature review, that there is sufficient controversy over low-level radiation health effects that such literature probably requires careful peer review. This assumption is supported by an interview with $\mathrm{Dr}$. George $\mathrm{H}$. Orrell of FEMA who reports that the agency's policy concerning national emergencies, including public information, is being revised and suggested that CIRRPC might consider involving itself in the discussion of how the public information on radiation is developed, packaged, and distributed.

There are some instances of interagency coordination. One such example is the cooperative effort of FEMA and the Nuclear Regulatory Commission (NRC) to rewrite the guidelines for utilities advising them of the kinds of information required by the public in case of emergency at a central nuclear generating station. The only other joint effort was one initiated in 1981 by FEMA and reportedly thwarted by DOE's objections to the plan. We received no reports of other cooperative, proactive projects.

There is available a small body of literature that provides what appears to be objective information on radiation health effects. DOE's "Understanding Radiation," FEMA's and Department of Labor's 
courses for specialized groups, International Atomic Energy Agency's (IAEA) publications, and the League of Women Voters Education Fund's "Nuclear Waste Primer." These publications cannot be described as being generally available, though the information contained in them is appropriate for the public.

In conclusion, the information that is available to the public on radiation health effects is sparse and difficult to obtain. The subject agencies do not have articulated policies related to information dissemination on the issue and are divided in their perceptions for such a policy. Activities are reactive and barely that. Some program staff at DOE and FEMA express concern over the public's lack of understanding of radiation, its sources, applications and health effects. This concern, however, is in contrast to the agencies' activities to address these concerns, other than in emergency situations, and to the existence of policies to support proactive education efforts. 


\section{INTRODUCTION}

The Committee on Interagency Radiation Research \& Policy Coordination (CIRRPC) is charged with coordinating radiation matters between agencies, evaluating radiation research, and providing advice on the formulation of radiation policy.

In December 1984, the CIRRPC Executive Committee began a series of meetings with senior staff of each member agency. Specific matters affecting agencies' programs were brought to light, problem areas identified, and insights gained into the major issues affecting federal government operations upon which CIRRPC must focus its attention.

As a result of these meetings and other similar informationgathering sessions with other concerned individuals, ten (10) national radiation issues were identified. One of these was public information and education.
"This issue has two distinct components. The first is the inadequacy of communications and interactions between the federal agencies, the scientific com- munity, the public and the various segments of the media on ionizing and non-ionizing radiation. The second component concerns the reduced flow of scientists trained in radiation from academe to the federal industrial sectors." 1 )

This study addresses the first component of the issue. Specific concern about "the need for a coherent and coordinated federal public information policy on radiation" 2/ in May, 1986, for member agencies' review. As a result of the comments received, the Executive Committee directed that several member agency representatives be contacted to determine what, if any, public awareness efforts on radiation health effects are currently underway and to describe the policies governing dissemination of information on this issue. The decision was made to limit the initial study to three agencies and to limit the scope of the study to fact finding.

This report contains a description of the methodology employed, a review of the literature obtained and a summary of the information gathered from interviewees at the Department of Energy, Department of Interior and the Federal Emergency Management Agency. Contained in appendices to the report are lists of the interview candidates for each of the agencies and a guideline for the interviews conducted. 


\section{METHODOLOGY}

The three agencies selected by the Committee on Interagency Radiation Research and Policy Coordination (CIRRPC) to participate in the study are the Department of Energy, the Department of Interior and the Federal Emergency Management Agency .

The first task of the contractor was to develop guidelines for the interviews. These guidelines were developed and reviewed with the ORAU/CIRRPC project manager prior to scheduling interviews. A copy of the guidelines is in Appendix A. They were designed to give focus to the interviews and to insure that information pertinent to policy definition and program activity related to radiation health effects would be obtained. The guidelines address the formation of policy, its articulation, evolution and perception by individuals in different program areas. The guidelines direct attention to the scope of activities underway, those perceived to be needed, and procedures for developing, reviewing and disseminating publications and other communications tools.

Interview candidates' names were provided to the contractor after the Chairman of CIRRPC had sent letters to the CIRRPC representatives at each of the three agencies explaining the purpose of the study and requesting suggested candidates for interviews. The ORAU/CIRRPC Program Director, followed with letters to the interview candidates providing background on the study and advising them that they would be contacted by the interviewer. Selection of specific individuals to be interviewed from the list of candidates was driven primarily by time considerations. The individuals recommended for interviews were mostly senior staff whose time was limited. In addition, interviews with one individual sometimes led to recommendations to talk with additional staff. In several instances, people in the agencies learned of the study and requested to be interviewed.

Individuals were selected as interview candidates on the basis of either their responsibility for program areas in which radiation health effects is a concern or their responsibility for dissemination of public information in the agency. Twentythree people were interviewed. A list of the interview candidates and those actually interviewed is contained in Appendix $B$.

Interviews were conducted in the offices of the various individuals over a period of six weeks. While there were no standard questions used for the interviews, the guidelines provided the content and focus for discussions. The length and qualilty of interviews varied considerably depending upon such factors as job function, tenure in job, and degree of interest in the topic of the interview. 
Concurrent with the conduct of the interviews, telephone requests for literature were made to each of the agencies. The first caller contacted the public affairs offices at the three subject agencies and requested literature relevant to health effects of low-level radiation. She was immediately referred to the Environmental Protection Agency by the Department of Energy and the Department of Interior. From the Federal Emergency Management Agency, she received one publication. We were concerned over these results and reported them to the ORAU/CIRRPC Program Director immediately. He requested that additional persons make calls and that we modify the instructions to the caller. The first caller had been instructed to request "information relevant to health effects of low-level radiation." Two callers subsequently were instructed to request "information relevant to health effects of radiation." The results of all inquiries are reported in the "Literature Acquisition and Review" section of this report. 


\section{DISCUSSION OF INTERVIEW FINDINGS}

This section of the report summarizes information and highlights some major findings for DOE, DOI and FEMA. Discussions are organized by agency. The purpose of this section is to synthesize the information gathered, by agency. Only in rare cases have we included attribution to an individual. A list of the interviewees for each agency is contained in Appendix $B$.

\section{Department of Energy}

Ten people were interviewed at DOE. Three are senior staff in the Office of Nuclear Energy, three are in the Office of Defense Programs, two are in the Office of Energy Research, and two are in the Office of Public Affairs.

\section{Major Findings}

A major finding to come out of interviews with staff at the Department of Energy is that there is no written policy regarding dissemination of information on radiation health effects. There is inconsistency between the perception of some staff in the Office of Nuclear Energy that there is a policy (albeit unwritten) of keeping the public informed and that of the office of Public Affairs, which reports that there is no policy. Many of those interviewed express concern over a lack of public understanding of the sources or the health effects of low-level radiation. Some indicate that the lack of public understanding threatens the entire nuclear options for peaceful or defense purposes. Interviewees also state that there is disagreement within the scientific community about the definition of low-level radiation and its health effects.

Although there are differences in perception of the existence of a policy, there is general agreement that there is a need for more public information, openness, and new or updated publications.

\section{Discussion}

Program staff in the Office of Defense Programs point to a long history, beginning in the early days of the Atomic Energy Commission, of informing staff and contractor employees about radiation effects. They point particularly to the efforts made in the Marshall Islands, where bilingual publications have been distributed and where medical records on natives of the islands have been maintained for more than thirty years to evaluate health effects. Program staff also report that there is a general practice at the various laboratories, research, production, and testing facilities of Defense Programs to make information on radiation and its health effects available to the local populace. None of these publications was available for review. 
Staff in Defense Programs express concern over a lack of public understanding of radiation, its sources and health effects and the impact this lack of understanding can have on the Department's programs. They also allude to the need for a clear definition of low-level radiation. One of their recommendations is to include in this study an assessment of what private sector organizations, such as the Atomic Industrial Forum, are doing to educate the public. They also express concern that because of the activities of groups such as Greenpeace and the Union of Concerned Scientists, the public receives one-sided information on nuclear weapons and on radiation effects.

The Office of Nuclear Energy perceives that there is a policy of keeping the public informed about nuclear energy, including health effects of low-level radiation, but acknowledges that it is of low priority. Actually, this view is in contrast to those of everyone else in the agency with whom we talked. And although the office of Nuclear Energy did provide the interviewer publications that are used to explain nuclear energy to the public, only one of three callers received one of the publications after having talked with four people who told her there was no information in the Agency on health effects of radiation. The perception of a policy, however, is explained by two public information activities undertaken by the office of Nuclear Energy in recent years. Two of the interviewees cite the west valley, N.Y. Low Level Waste Demonstration Project community information program as the kind that can be successful over a long period of time.

When the site for disposal of low-level waste at West Valley, New York, was approved, DOE issued press releases advising local citizens of the fact. They also distributed to the press comprehensive fact sheets which defined environmental assessment, the methodology that would be used in disposing of lowlevel waste, the criteria used for selection of the site, and the environmental impact during and after construction.

Although the fact sheets we obtained contain no information on health effects of low-level waste, the West Valley, New York Demonstration Project does provide a model that might be employed successfully to address health effects of radiation for specific projects.

A second public information plan described by interviewees in the Office of Nuclear Energy does contain information on health effects of radiation. The Uranium Mill Tailing Radiation Control

Act of 1978 (P.L. 95-604) specifically calls for public participation of affected states and Indian tribes for the cleanup of designated, abandoned or inactive uranium mines. The need to inform citizens so that they could participate knowledgeably in the decisionmaking process prompted development of that public information plan in June 1984 . 
The plan spells out policies and procedures for disseminating information pertinent to the Law, scope of the project, site priorities, economic, health and environmental impacts, cooperative agreements, and other project information. Levels of responsibility are well-defined and a variety of communications tools identified as possible components of the public information program. Emphasis is on timely, factual dissemination of project information.

Although we were provided a copy of the plan, it is unclear what communications tools have been developed and disseminated.

Several of the interviewees suggest that a plan similar to that developed for the West Valley project would be useful for nuclear facilities to keep the public informed and confident about the operational safety of plants.

Staff from the Office of Energy Research describe their role as conducting unclassified research and making information available for publications such as a series on "Understanding the Atom" which was written in the 1950's and 1960's. To the best of our knowledge, these publications are out of print.

Interviews with staff in the office of Public Affairs confirm that there is no written policy nor is the need for one expressed. Interviewees concede that there are no new or updated publications on radiation health effects and that it might be time to update them.

\section{Department of Interior}

Eight people at DOI were interviewed. One is the Assistant Secretary for Policy, Budget and Administration; three are in Hazardous Materials, Bureau of Land Management; one is in the Bureau of Indian Affairs; two are in the Fish and wildlife Service; and two are in the U.S. Geologic service.

\section{Major Findings}

All interviewees at the Department of Interior report that there is no written policy regarding information dissemination on radiation health effects. Most describe consideration of health effects outside their scope of activity and identify other agencies as having responsibility for health issues. They emphasize the diversity of responsibility the agency has and suggest that a central policy might be inappropriate. Only one individual in the agency describes a program, which is still being developed, to educate the public about radiation health effects. 


\section{Discussion}

In the Bureau of Indian Affairs, Dr. Kerulis is preparing a proposal for a public education program concerning a broad spectrum of hazardous materials for students up to 12 years of age. His interest in developing the proposal is an outgrowth of a study he wrote in collaboration with J. S. Boyce, "Initial Inventory and Evaluation of Health and Safety Issues Associated with Abandoned Uranium Mines." (The report is reviewed in the Literature Acquisition and Review section of this report.) In the discussion and recommendations section of the report, the authors state:

"The public's perception and knowledge of
radiological hazards must be carefully considered
and understood before any interim or final actions
are taken. 3 ]
"It is believed these issues [long- and short-term
risks associated with abandoned uranium mines] can
be resolved by taking a careful, measured approach
in assessing public awareness, risk assessment,
community relations and public education and other
considerations. Public concern about nuclear war,
the nuclear winter theory, and cancer deaths
associated with exposure to radiological materials
including radon-daughters, and the general unsettled
public feeling that all radiation is dangerous may
create adverse public relations. "4

The U.S. Geologic Service (USGS) cites a fact sheet on toxic waste as being relevant to our discussion, but the fact sheet does not deal with health effects of ground water contamination. We could find no literature in the agency relating to health effects of radiation. Most frequently, callers were referred to HHS, though one caller was referred to the Department of Labor.

\section{Federal Energency Managenent Agency}

Five interviews in FEMA were conducted. One was with the senior policy advisor in the office of the Director; two were with deputy associate directors; one was with the associate director of the Emergency Management Institute, National Emergency Training Center, in Emmitsburg, MD; and one was with the acting director of the office of Public Affairs.

\section{Major Findings}

FEMA has no written policy regarding dissemination of information on radiation health effects, but guidance exists under a subset of the national emergency policy which specifies what information should be disseminated in the event of a national nuclear emergency. FEMA is revising its national emergency 
policy and Dr. Orrell, deputy associate director, suggests that CIRRPC might consider involving itself in the discussion of how information on radiation is developed, packaged and distributed. FEMA has developed a great deal of information on radiation health effects which is contained in two courses and one other publication designed for public dissemination. It is the only agency to report any interagency activity related to radiation health effects. Interviewees consistently report a need to improve public understanding of radiation and its health effects.

\section{Discussion}

FEMA interviewees cite public reaction to the Three Mile Island (TMI) accident and the more recent and serious Chernobyl accident as indicators of the lack of public understanding of radiation and the health effects of different levels of exposure.

Following the TMI incident, FEMA established joint public information centers at each of the nuclear powerplants. The agency oversees annual or more frequent exercises to ensure that the centers are prepared to respond appropriately in case of an emergency. FEMA also works with the Nuclear Regulatory Commission (NRC) to revise guidelines for information dissemination at nuclear powerplants.

FEMA reports the only attempt at interagency activity to develop a comprehensive information program on radiation. The acting director of the office of Public Affairs reports that in 1981 FEMA developed a public information plan on "Nuclear Power and Radiation: A Matter of Fact," for a national program. FEMA proposed it to the Federal Radiological Preparedness Coordinating Committee, but the program reportedly never came to fruition because it was thwarted by DOE. A copy of a 1981 FEMA newsletter is contained in Appendix $C$ of this report. There is no other evidence of attempts to initiate interagency programs to disseminate information on radiation health effects.

Seemingly, the most active effort at disseminating information on radiation health effects exists in the National Emergency Training Center. The associate director reports that the center trains about one hundred thousand people per year; he estimates that the total reached through training at the local level increases that figure to about one million per year. The courses, which are reviewed in the Literature Acquisition and Review section of this report, contain information on radiation health effects which he describes as being frequently revised.

Publications described as being generally available to the public, "Emergency Management, U.S.A.." and a programmed home study course, "Radiological Monitoring," are not, according to our experience, generally available. They are available from the Emmitsburg facility, but there is no reason to assume that most citizens are aware of the existence of the facility or the publications. 


\section{LITERATURE ACQUISITION AND REVIEM}

Literature was acquired in two ways: by interviews and through telephone requests. Acquisition of literature during interviews was unsolicited. The interviewer accepted whatever publications the interviewee chose to give him. On the other hand, all three callers were instructed to call the Department of Energy, Department of Interior and the Federal Emergency Management Agency and request information on health effects of radiation. The first caller was instructed to inquire specifically for publications related to low-level radiation, but when she was told that there were no publications, the second and third callers were instructed to broaden the question to include all levels of radiation. Referral to other agencies was not anticipated and callers received no instructions regarding making additional calls. It was an individual decision. The first and third callers followed up with calls to the Environmental protection Agency when so directed by individuals at FEMA and the Department of Interior. Individuals at the Department of Interior also referred two of the callers to the National Institutes of Safety and Health (NIOSH). One caller contacted NIOSH, but was told that its publications are primarily technical papers. One caller was referred to Department of Labor.

Interestingly, all three callers received different publications. The only exception was that callers one and two were referred to EPA's two publications on radon (OPA-86-005 and OPA-86-004). Otherwise, callers were referred to entirely different people in the agencies and received entirely different publications. All three callers began by calling either the public affairs office or the publications office. Information received from those offices was inconsistent. For example, at DOE, one caller was referred immediately to the EPA; the second was referred within DOE to Environmental Health and Safety and then to Nuclear Energy. The third caller was referred directly to EPA.

One might conclude from these calls that the subject agencies of this report do not perceive dissemination of information on radiation health effects to be within their purview, but primarily within that of EPA. Further, one might also conclude that individuals in the public affairs offices and the publications offices of the subject agencies are unaware of the publications pertinent to radiation health effects that do exist in their own agencies.

\section{Literature Review}

Publications are briefly reviewed, by agency. General subject matter, length of document and format, and our perception of the intended audience are noted for each publication. There has been no attempt to evaluate the publications. At the beginning of the review of literature of each agency, we have made some 
observations about the publications. Where identifying numbers and dates appear on the publication, they are noted in the individual bibliographical entry.

Publications marked with one asterisk were received as a result of telephone inquiry. The one publication received by the interviewer and as a result of telephone inquiry is identified by a double asterisk. All other publications were obtained by the interviewer.

\section{U.S. Department of Bnergy}

of the publications listed, four contain information related to radiation health effects. Most of the publications are undated, so it is difficult to relate them to current or past policy regarding dissemination of information on radiation health effects. Only one of the publications which contains relevant information was made available to one caller, on the basis of a public inquiry.

* Atoms to Electricity. DOE/NE-0053. 5 x 8 format, 61 pages. November 1983. Audience: general public.

Describes basic technology of nuclear fission power reactors, nuclear fuel cycle and the role of nuclear energy in the U.S. economy and the part it plays in meeting our energy demand.

Low Level Radioactive Waste: BUILDING A PERSPECTIVE. Atomic Industrial Forum, Washington, D.C. $8 \frac{1}{2} \times 11$ format, 33 pages, plus appendices. Audience: general public.

Describes the origins of low-level radioactive waste, relating waste to the contributions radioactive materials make to our lives (medicine, diagnostics, fire detection, power generation, etc.). Also identifies the volume and radioactivity generated by sector (nuclear power plants, academic/medical, government, and industrial). Defines nuclear terms, and reports federal standards for alternative means of disposing of lowlevel waste. Lists sources of information and contains a bibliography.

Low-Level Waste Management. The National Program for Low-Level Radioactive Waste Management. Program Document B093.0982.R.2M EG\&G Idaho, Inc., Idaho Falls, ID. $8 \frac{1}{2} x 11$ format, 34 pages. Audience: unclear.

The publication is divided into seventeen one- to two-page discussions of low-level radioactive waste. It defines lowlevel radioactive waste, its origins, waste treatment and disposal and pertinent regulations. It also has a one-page discussion of radiation exposure and a one-page description of the primary types of ionizing radiation. 
Managing the Nation's Nuclear Waste. U.S. DOE/RW-0036. $8 \frac{1}{2} \times$ Il format, 8 pages. Audience: general public.

This publication defines radioactive waste and discusses briefly the Nuclear Waste Policy Act, the selection of repository sites, and defines a geologic repository. Finally, it discusses who pays for high-level radioactive waste management.

Nuclear Energy Economics. DOE/NE-0061. $33 / 4 \times 81 / 2,16$ pages. Audience: general public.

Reviews the cost factors in producing electricity, the problems with projecting future need for generating capacity, and the cost of delays and interest in building new power plants. It states that nuclear energy is generally less expensive than other kinds of generating plants, but later modifies that statement in a discussion of the percentage of generating capacity provided by nuclear.

Nuclear Power in Space. $33 / 4 \times 81 / 2,27$ pages.

Addresses history of nuclear power in space.

Nuclear Power Plant Safety: DESIGN AND PLANNING. DOE/NE-0069. $33 / 4 \times 81 / 2,16$ pages. Audience: general public.

Reports on design and planning in safety, development of emergency response planning and a review of the Three Mile Island accident. While the pamphlet reports that there was no injury to staff or public, it does not quantify the release of radioactivity from the accident.

Nuclear Powerplant Safety: OPERATIONS. DOE/NE-0070. $33 / 4 \mathrm{x}$ $81 / 2,15$ pages. Audience: general public.

Reports on the training of powerplant personnel, security, and regulations affecting powerplant safety. It also presents data on sources of radiation exposure for the public, including that from power plants.

Remedial Action Program. U.S. Department of Energy. $8 \frac{1}{2}$ x Il format, 19 pages. Audience: general public.

This publication reviews the history of the problem of radioactive contamination stemming from the days of the Manhattan Project. It also has a brief section on contamination pathways, but does not discuss the levels of contamination that constitute a threat to animals or humans, either directly or through the food chain. The publication is devoted primarily to a discussion of the various legislative acts which have established the Remedial Action Plan. 
The Harnessed Atom. DOE/NE-0072. $8 \frac{1}{2} \times 11$ format, 132 pages. Audience: adolescents.

This is a kit produced for use in middle schools. It contains lessons divided into three major sections: Energy and Electricity; Understanding Atoms and Radiation; and the Franklin Nuclear Power Plant. Finally, there is a review of major issues related to all three units of study. The document also contains a glossary of terms associated with nuclear energy. There is a simple explanation of what radiation is, how it is measured, and how people are exposed to radiation. Federal standards for exposure are given, but there is no discussion of health effects.

The History of Nuclear Energy. DOE/NE-0068. $33 / 4 \times 8$ 1/2, 20 pages. Audience: general public.

Presents a discussion of the discovery of fission, the first self-sustaining chain reaction, and the development of peaceful civilian applications, as well as key dates and a brief list of references.

The Nuclear Waste Primer. A Handbook for Citizens. 90 pages. The League of Women Voters Education Fund. 1985. Audience: general public.

The ninety-page handbook contains a discussion of sources of radiation, the hazards it creates, past and present waste management, the politics of radioactive waste management, and the role for citizens in waste management. The book contains a four-page section on the three primary types of ionizing radiation, the measurement of radiation and the biological effects of radiation. The publication draws primarily on information from government agencies, but also contains some information from private sector sources, such as the Union of Concerned scientists.

**Understanding Radiation. DOE/NE-007433/4 x 8 1/2, 17 pages. Audience: general public.

Defines radiation and its sources, explains how to measure radiation exposure and discusses the health effects of radiation. Also presents a very brief discussion of applications of nuclear diagnostic techniques.

\section{Department of Interior}

All the publications obtained from DOI are technical publications. None is intended for public dissemination, but the first study cited contains information which would be valuable to the local populace, hikers, etc. 
Initial Inventory and Evaluation of Health and Safety Issues Associated with Abandoned Uranium Mines. F. J. Kerulis and J. S. Boyce, Bureau of Land Management, 1985. 19 page report with appendices.

This document reports the findings of a study of the health and safety issues associated with abandoned uranium mines. The report concludes that entry into abandoned uranium mines presents both physical and radiological hazards, that the waste rock used in construction presents health hazards to future inhabitants, and that water contaminated with radionuclides is sometimes associated with abandoned uranium mines. The report goes on to state that the public does enter abandoned uranium mines and that domestic animals and cattle are grazed and watered on superficially reclaimed land. The report contains an appendix which provides detailed information on radiological hazards. The report contains in a separate appendix two newspaper articles from the High Country News on the economic and health impact of the radioactivity associated with abandoned uranium mines.

Radionuclide Levels in Cattle Raised Near Uranium Mines and Mills in Northwest New Mexico. S. C. Lapham and Jere B. Millard, New Mexico Environmental Improvement Division and J. M. Samet, New Mexico School of Medicine. 1986. 50 pages.

The paper reports on a study conducted in two locations near Ambrosia Lake, New Mexico, in which radionuclide levels in cattle were evaluated. The purpose of the study was to determine whether cattle grazing in areas with uranium mining or milling activity have tissue concentrations of radionuclides that are significantly above background and whether their grazing regularly in these areas could expose humans to excessive internal doses of radiation. The findings were inconclusive due to a small sample and other limitations of the study.

Role of Earth Sciences in the Disposal of Radioactive Waste. Reprint from USGS Yearbook, Fiscal Year 1977, 5 x 8 format, Il pages.

Discusses the possible disposal methods of radioactive waste and the unresolved problems, such as interaction of host media and waste in three principal categories: mechanical, mineralogical and hydrologic.

Water Fact Sheet. U.S. Geological Survey. 1983.

This fact sheet describes the danger of ground-water contamination and reports on the purpose and activities of the Toxic Waste-Ground Water Contamination Program, to provide other federal and state and local governments with earth-sciences information "to improve waste disposal practices and regulations." 


\section{FEDERAL EMERGENCY MANAGEMENT AGENCY}

The home study courses reviewed below generally contain a teacher's guide, student manual, and final exam. They are available to course participants rather than to the general public. However, protection in the Nuclear Age contains information from these courses relevant to radiation health effects and safety procedures. All publications are dated and thus can be related to agency policy for the period.

Emergency Management U.S.A. FEMA. HS-2/May 1986.

This publication is a home study course in learning the dangers of various disasters, how to recognize them, plan for them and function during these emergency situations. The course contains a lengthy section on what to do in case of nuclear attack. It describes types of ionizing radiation, the probable exposure for people relevant to proximity to attack as well as other dangers posed by a nuclear blast. It describes the physical symptoms one can anticipate based on level and duration of exposure, provides descriptions of different kinds of shelters, identifies high-risk areas for nuclear attack, and provides checklists for shelters and for evacuation.

Fundamentals Course for Radiological Monitors. FEMA. SM 81 . September 1984.

FEMA has developed an instructor's manual, study guide for students and final exam for training radiological monitors. The course covers basic information on radiation and radioactivity, peacetime accidents involving radiation and nuclear attack. It covers measurement, the instrumentation used, basic principles of radiation protection and the care of victims in a peacetime radiation accident.

Fundamentals Course for Radiological Response Teams. FEMA SM 82. September 1984 .

This publication covers radiological emergencies and radiological protection system on an operations level. It focuses primarily on the fundamentals of radiation, biological effects and risks and the assessment and management of radiological emergencies. It contains the most comprehensive information on radiation health effects of any of the course materials contained in this bibliography, relating specific exposure levels to discrete health effects.

Hospital Emergency Department Management of Radiation Accidents. FEMA. MaY 1984.

This course contains background information on radiation and radiobiology, radiation protection principles, instructions for preparing to receive the radiation accident victim, and 
hospital emergency care of the radiation accident patient. specific techniques for evaluation and treatment are reviewed.

* Protection in the Nuclear Age. H-20/June 1985. FEMA. $5 \times 8$ format, 38 pages.

The information contained in this booklet addresses nuclear emergencies: the effects of nuclear weapons, warning, population protection, and shelter living. The section on nuclear weapons contains information on radiation exposure levels and their health effects.

* Radiation safety in Shelters. FEMA. CPG-6, 4, September 23, 1983. 73 pages plus appendices.

This publication is designed for people outside the immediate area of nuclear attack. It instructs in the measurement of radiation levels, treatment of individuals exposed to radiation, symptomotology, minimizing radiation exposure, and a variety of safety procedures. It is organized so that information can be quickly found in case of emergency.

* Radiological Monitoring: A Home Study Course. FEMA. Ss-3, February 1982. 275 pages.

This home study course is designed to train radiological monitors who would take measurements to be used by a radiological defense officer in the event of a nuclear emergency. It covers fallout effects and exposure guidance, RADEF instrumentation, protective measures, exposure and exposure rate calculations, radiological monitoring procedures, responsibilities and reporting techniques.

* Understanding Nuclear Attack. FEMA. A 9-page excerpt from a FEMA publication (unidentified).

This excerpt is a repeat of the information contained in the documents previously reviewed, but in a shorter version. It contains information on what to do in case of a nuclear attack and discusses radiation exposure, long- and short-term effects of radiation exposure, and safety procedures.

\section{Environmental Protection Agency}

Although the Environmental Protection Agency is not one of the agencies this study covers, we believe that literature obtained from the agency in response to referrals from other agencies should be contained in this report. Two of the callers received the two publications (OPA-86-004 and OPA-86-005) on radon cited below. The third caller did not receive those publications, but received all the others contained in this review. 
* A Citizen's Guide to Radon: What It Is and What To Do About It. EPA. OPA-86-004. $5 \times 8$ format, 13 pages. Audience: general public.

As the title implies, the publication defines radon, its origins, and its health effects. It also explains how radon gets into homes and how to detect it. Finally, it instructs the reader of the action to take with regard to various levels of radon in his home.

* Assessment of Potential Radiological Health Effects from Radon in Natural Gas. EPA-520/1-73-004. 60 pages. Audience: scientists/health care professionals/sophisticated laymen.

This document reports on radon concentration in natural gas, the population exposure and potential health effects and considers methods for reducing health effects. The study concludes that control of radon levels in gas would cost over $\$ 100$ million for each reduction of one health effect and that a requirement for "such controls would not be cost effective on a national basis."

* Estimate of the Cancer Risk Due to Nuclear-Electric Power Generation. EPA Technical Note. ORP/CSD-76-2. 8 $\frac{1}{2} \times 11$ format, 35 pages including bibliography. Audience: professional/ technical.

The document reports on three sources of radiation exposure: occupational exposure to radiation workers; exposure of the general population fxom routine releases of radioactivity to the environment; and exposure due to accidental releases of radioactivity. The conclusions report estimates of risk per gigawatt-year, but offer the opinion that "it is beyond the state of the art to compare these risks to the cancer risks from other forms of electrical energy production." The authors of the publication also call for assessing health risk independent of societal issues.

* Estimates of Ionizing Radiation Doses in the United States: 1960-2000. EPA-ORP/CSD 72-1. $8 \frac{1}{2} \mathrm{X}$ 1I format, 171 pages. Audience: technical/professional.

The report is a product of the Special studies Group, a successor to the Federal Radiation Council. Its members included representatives from the Department of Defense, Department of Health, Education and Welfare, Atomic Energy Commission and the Office of Water Programs, Environmental Protection Agency. The report summarizes the radiation exposure for the period 19601970 and makes predictions about public exposure to radiation through the year 2000. It discusses exposure experience and predictions on the basis of source: environmental radiation, which includes natural radiation, global fallout from nuclear tests, peaceful applications of nuclear explosives, nuclear electric power and government facilities; medical radiation; 
occupational radiation; and that received from miscellaneous sources such as televisions and consumer products.

* Radiological Quality of the Environment. EPA-520/1-76-010. $8 \frac{1}{2} \times 11$ format, 245 pages. Audience: technical/professional.

This document compiles information obtained over the previous 15-year period on individual and population radiation doses. Data on sources of radiation are reported in 25 categories. The report was prepared in response to EPA's mandate to "determine the status of radiation data nationwide, to analyze these data in terms of individual and population doses, and to provide guidance for improving radiological data."

* Radon Reduction Methods: A Homeowner's Guide. EPA-OPA-86005 . 5 × 8 format, 23 pages. Audience: general public.

The publication is designed for homeowners who have had their homes tested for radon and need to reduce radon levels. It provides instructions on nine methods for reducing radon levels. For each method, the publication provides an explanation of how it works, cost, efficacy and procedures to follow. It contains a brief discussion about selection of contractors and presents a comparison of operating costs, installation cost and maximum possible reductions of radon levels for the nine methods. The publication also contains a list of EPA regional offices.

\section{Department of Labor}

The third caller was referred to the Department of Labor by the Department of Interior. The publications received as a result of her call to the Mine Safety and Health Administration, Directorate of Technical support at that agency, are reviewed briefly below. Most of the publications are in fact sections from unidentified documents.

* Biological Effects of Ionizing Radiation. RA.PH.bi.21.10.57. 11 pages including bibliography. Audience: unclear, suitable for educated, but non-specialized audience.

Reports on the sequential pattern of biological effects, the determinants of biological effects, and the clinically observed effects of exposure to ionizing radiation.

* Correlation of Units of Activity and Exposure. RA. IA.11a.7.59. 8 pages. Audience: technical.

Reports dose rate resulting from exposure to external sources of radioactive material. 
* Facts About Low-Level Radiation: A Companion Leaflet to RADIATION - A FACT OF LIFE. International Atomic Energy Agency. Distributed by the American Nuclear Society. 18 pages, $5 \times 8$ format. Audience: general public.

Addresses low-level radiation exposure and the sources of exposure, but focuses primarily upon the controversy within the scientific community regarding the health effects of low-level radiation and cites several studies that support the need for a broader attack on reducing health and genetic risks--one not restricted to concentrating on ionizing radiation or other individual hazards. The publication also describes the review process for studies on radiation health effects.

* Radiation: A Fact of Life. International Atomic Energy Agency. printed and distributed by the American Nuclear Society. 14 pages, $5 \times 8$ format. Audience: general public.

Defines radiation and the types of radiation, sources and doses. It also discusses standards for maximum radiation doses per year and how they relate to actual exposure for the general public. Addresses the controversy over scientists' perception for the risks of low-level radiation, discusses the benefits of radiation, the work of the IAEA, and discusses relative risks from nuclear powerplants and from oil- and coal-fired powerplants.

* Radiation--Underground Only. Excerpt from CFR Ch. 1 (7-1-85), paragraph 57, 5037, pp. 390-392. Audience: technical.

Provides guidelines for monitoring radon daughter exposure in uranium mines being actively mined.

* Units of Radiation Dose. RA.IA.10b.2.60. 4 pages. Audience: technical.

Defines "roentgen" and "rad" and discusses the relative biological effectiveness of radiations of different types. Finally, it defines "rem."

* What Are the Harmful Effects of Radiation? 12 pages. Audience: new radiographers.

Provides a brief history of knowledge of the effects of radiation exposure. Presents case histories of individuals who have been exposed to excessive amounts of radiation through carelessness, lack of understanding of radiation or deliberate exposure. Discusses prompt effects of radiation, giving examples of injuries and how they occurred; radiation sickness; and the delayed effects of radiation. 
* What Is Radiation? A Manual for Training Radiographers. 7 pages.

Presents a definition of radiation and discriminates $x$-ray and gamma ray radiation and defines ionization. Presents information on radiation doses, the sources of radiation (natural and occupational). 


\section{SUMMARY}

Our findings indicate that there is no clearly articulated policy on dissemination of information on radiation health effects for any of the three subject agencies. The only agency that has a policy of updating information on radiation health effects is FEMA, as part of its training for national emergencies. There is virtually no interagency communication on the issue except through CIRRPC. There is inconsistency within agencies as to the existence of policy and the perception of need for a policy.

There is a consensus that there is a public lack of understanding of radiation and its health effects. Some interviewees state that this lack of understanding is a threat to all nuclear programs. While FEMA has courses to train individuals for emergency situations, there are no efforts to provide a background of public understanding of the basic issues related to radiation against which "emergency information" might be better understood.

Interviewees appear to be unaware of the number or kinds of requests for information. Furthermore, some operate under the illusion that the agency's or office's information is generally available to the public, though our efforts to obtain the information refute that assumption. There is an apparent dearth of procedures to ensure that program information related to radiation health effects reaches the public.

In summary, there is a perceived need for dissemination of objective information on radiation health effects and for an educated public, but there are no proactive efforts to accomplish that education other than the programs that exist for emergency preparedness. 


\section{FOOTNOTES}

I/ "Report on Identification of Federal Radiation Issues (A Report to the Federal Coordinating Council for science, Engineering, and Technology)." Committee on Interagency Radiation Research and Policy Coordination, March 21, 1986. p. 10.

\section{2/ Ibid.}

3/ Kerulis, F. J. and Boyce, J. S. "Initial Inventory and Evaluation of Health and Safety Issues Associated With Abandoned Uranium Mines." Bureau of Land Management, Department of Interior, 1985. p. 20.

4/ Ibid. . p. 20 . 
APPENDICES 
APRENDIX A

INTERVIEW GUIDELINES

A 


\section{INTERVIEH GUIDELINES}

The following will serve as a guideline for interviews with public affairs and program staff of the target agencies:

A. POLICY

Identify the department's current policy concerning public awareness activities related to radiation health effects.

Describe how the policy has evolved through the years.

Determine whether policy is currently under review or whether it has recently been reviewed.

Describe the elements that constitute the policy.

Describe the process for policy implementation.

Obtain opinion of the strengths and weaknesses of the policy.

B. PROGRAMS

Identify the full range of public awareness activities related to radiation health effects in the department.

Identify means of information dissemination, target audience and frequency distribution.

Describe generic content of the information which is distributed.

Describe how information is prepared, at whose initiative and the review procedures for the information.

Provide a brief history of the development of these activities.

Describe with what frequency activities are reviewed and identify the most recent review of activities.

C. GENERAI COMMENTS

Determine whether there are areas on which information is not currently disseminated.

Determine whether staff consider currently available information adequate (up to date, complete).

Describe most frequent requests for information (content areas) and the source of requests. 
APPENDIX B

LIST OF INTERVIEW CANDIDATES 


\section{DEPARTMENT OF ENERGY}

- *GAIL L. BRADSHAW, DIRECTOR OF PUBLIC AFFAIRS.

- *S. J. BRAZELY, PROJECT OFFICER, URANIUM MILL TAILINGS PROJECT, OFFICE OF NUCLEAR ENERGY.

- *DAN BUTLER, PUBLIC AFFAIRS OFFICER, OFFICE OF NUCLEAR ENERGY.

- *JOSEPh A. COLEMAN, DIRECTOR OF WASTE TREATMENT PROJECT, DEFENSE PROGRAMS.

- Charles P. DELISi, Associate DiRector of heALTh AND ENVIRONMENTAL RESEARCH.

- *JAMES F. DECKER, DEPUTY DIRECTOR OF ENERgY RESEARCH.

- LARRY FORSYTHE, DIRECTOR, ENVIRONMENTAL SAFETY AND HEALTH, DEFENSE PROGRAMS.

- KEVIN MULLEN, PROGRAM ANALYST, ENVIRONMENTAL ANALYSIS, ENVIRONMENTAL HEALTH AND SAFETY.

- *KRISTINE MORRIS, SPECIAI ASSISTANT FOR POLICY, OFFICE ASSISTANT SECRETARY FOR DEFENSE PROGRAMS, DOE.

- MARCIA B. PROCTOR, DIRECTOR OF DOCKET AND PUBLICATIONS.

- DONALD OFTE, PRINCIPAL DEPUTY ASSISTANT SECRETARY FOR DEFENSE PROGRAMS.

- *DAVID ROSSIN, ASSISTANT SECRETARY FOR NUCLEAR ENERGy.

- *BRIAN SIEBERT, DIRECTOR, OFFICE OF INTERNATIONAL AFFAIRS, DOE.

- ROBERT J. STERN, DIRECTOR OF ENVIRONMENTAL GUIDANCE.

- *JOHN SULLIVAN, DIRECTOR, DIVISION OF PUBLICATIONS.

- *J. W. THIESSEN, DEPUTY ASSOCIATE DIRECTOR, HEALTH AND ENVIRONMENTAL RESEARCH, OFFICE OF ENERGY RESEARCH.

- MARY L. WALKER, ASSISTANT SECRETARY FOR ENVIRONMENTAL HEALTH AND SAFETY.

* INDICATES INTERVIEWED. 


\section{DEPARTMENT OF THE INTERIOR}

- *BRUCE BLANCHARD, DIRECTOR, OFFICE OF ENVIRONMENTAL POLICY REVIEW AND ASSISTANT SECRETARY FOR POLICY, BUDGET AND ADMINISTRATION.

- *SARA GEROULD, ENVIRONMENTAL SPECIALIST, FISH AND WILDLIFE SERVICE.

- BERNARD R. HYDE, JR., CHIEF OF HAZARDOUS MATERIAL STAFF, BUREAU OF LAND MANAGEMENT.

- *DONOVAN KELLY, PUbLIC AFFAIRS OFFICER, U.S. GEOLOGIC SURVEY.

- *FREDERICK J. KERULIS, MANAGER, HAzARDOUS MATERIALS, BUREAU OF INDIAN AFFAIRS.

SPECIALIST, BUREAU OF LAND MANAGEMENT.

- *CLEMENT F. SHEARER, SPECIAL ASSISTANT FOR NATIONAL HAZARDS, U.S. GEOLOGIC SURVEY.

- *ROBERT SHULENSKI, PHYSICAL SCIENTIST, HAZARDOUS MATERIAL STAFF, BUREAU OF LAND MANAGEMENT, DOI, WAS SUBSTITUTE.

- *ROBERT M. WILSON, ENVIRONMENTAL PROTECTION SPECIALIST, BUREAU OF LAND MANAGEMENT.

* INDICATES INTERVIEWED. 


\section{FEDERAL EMERGENCY. MANAGEMENT AGENCY}

- *GERALD BOYD, ASSOCIATE DIRECTOR, EMERGENCY MANAGEMENT INSTITUTE, NATIONAL EMERGENCY TRAINING CENTER, EMMITSBURG, MARYLAND.

- *JAMES C. KELLETT, SENIOR POLICY ADVISOR, OFFICE OF THE DIRECTOR.

- *DAVID McLAUghlin, DEPUTy ASSOCiATE DiRECTOR.

- *PEG MALOY, ACTING DIRECTOR, OFFICE OF PUBLIC AFFAIRS.

- *GEORGE H. ORRELL, DEPUTY ASSOCIATE DIRECTOR.

- CARL SIEBENTRITT, CHIEF, RADIOLOGICAL INSTRUMENTAL BRANCH.

* INDICATES INTERVIE 


\section{APPENDIX C}




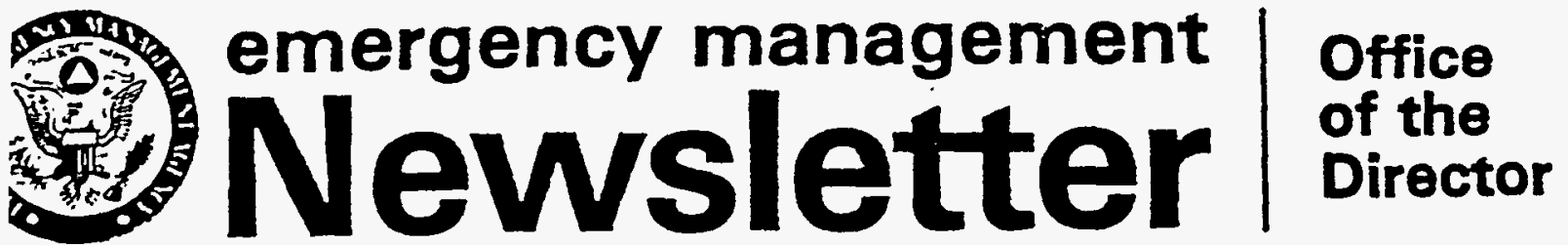

Foderal Emergency Management Agency / Washington, D.C. 20472 / November 6, 1981

\section{UCLEAR POWER AND RADIATION: A MATTER OF FACT}

:lear power has the dubious distinction, ording to some studies, of being per. ied as the greatest risk to which people exposed, easily outstripping handguns, lorcycles, alcohol, or commercial aviation. 'el nuclear energy is a reality in the ted States today. Nuclear power plants producing nearly 12 percent of the na. i's energy, and nuclear power is a cor. stone (along with coal) of the country's ns to meet its energy needs in the face of unishing oil supplies.

While there are a multiplicity of safeguards all U.S. nuclear plants, Three Mile Island ived there is the potential for a high-level liation release.

Vuclear power may be perceived as the yatest risk to which people are exposed. I most of these same people have only a Jimentary understanding - if that-of clear power. This lack of knowledge may caused by the fact that the technology is phisticated and is aided by the concept It invisible and powerful radiation is laced in mystery.

Understanding is clouded further by fears oked by nuclear power's supposed links to e destruction at Hiroshima and Nagasaki id those aroused by a perceived potential ilastrophe at Three Mile island.

Still, there are large segments of the spulation which hall nuclear power as an efzient. sale. and clean answer to America's nergy shoriages and a key 10 a continued conomic growth and well being. At the oposite end of the spectrum, there are, of ourse, anti-nuclear voices which warn of anger to life and health.

Clearly, Americans living near nuclear ower plants need to know more about uclear power and radiation - and they need o know it before an accident occurs, if the iformation is to help people respond rationlly and calmly.

Recognizing this need. FEMA-as head of he interagency Federal Radiological 'reparedness Coordinating Committee-has :ommitted itself to an extensive program to rducate the public about nuclear power and adiation.

To achieve objectivity, materials developed or the program are being reviewed carefully iy a wide range of experts representing both jovernment and non-government organiza. rons, with both pro-nuclear and anti-nuclear sympathies. A sampling of the comments eceived to date would indicate that the naterials will attain that balance.

\section{The Plan}

Planning a national public education program on nuclear power and radiation entails several stages: review of existing educational materrals on the subject to distinguish suc- cessful approaches from unsuccessiul ones; consultation with the state and local emergency planners who will use the materials to assess their needs and obtain theít suggestions; identification of the target

\section{INFORMATION PROGRAM MATERIALS}

- The "Nuclear Power and Radiation: A Matter of Fact" box, specially designed to contain samples of each information program component, including the public education resource handbook, printed materials, and audiovisuals.

- A catalog/order form containing illustrations and descriptions of the information program components and instructions for obtaining bulk copies.

- "Getting Out the Facts," a public educa. tion resource handbook designed for use by regional, state, and local emergency planners. The handbook presents an overview of the "Nuclear Power and Radiation: A Matter of Fact" program and provides emergency planners with detailed guidelines for educating residents in their communities, including suggestions for distributing materials and tips on working with the media.

- "Nuclear Power and Radiation: A Matter of Fact." an illustrated booklet which addresses the dual issues of nuclear power and radiation in an in-depth, yet nontechnical way.

- "Plain Facts About Nuclear Power and Radiation." an illustrated, fold-out pamphlet which contains a shorter, simplified treatment of nuclear power and radiation.

- A large and colorful reference wall char which will serve as a ready source of basic facts and statistics on nuclear power and radiation, for use in classrooms, libraries, offices, and health clinics.

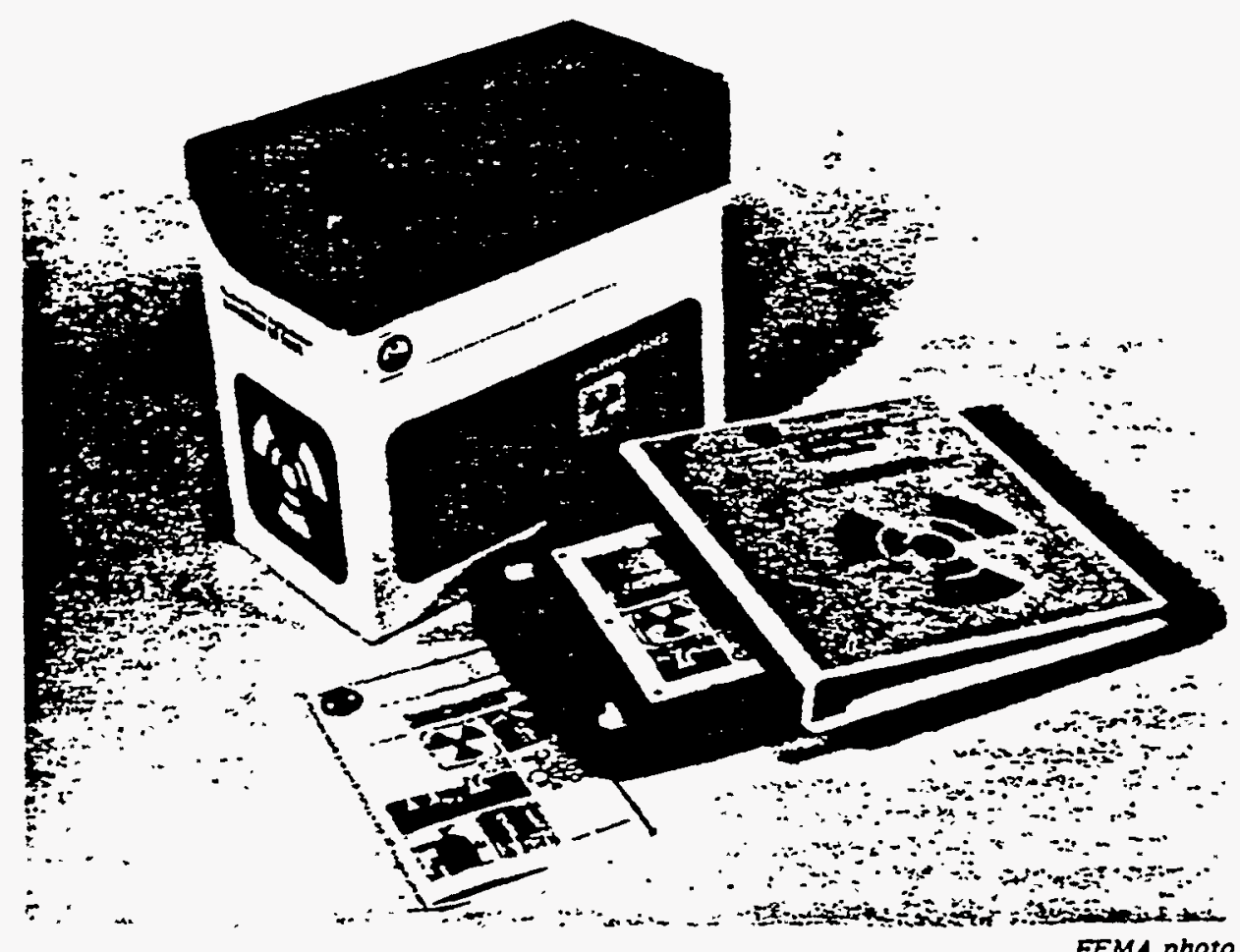

FEMA photo

$c-i$ 
audiences who are the focal point of the effort; definition of the central message areas which must be communicated; and, finally, determination of the best methods or vehicles for getting the messages to the appropriate audiences.

FEMA's survey of existing educational materials on nuclear power and radiation revealed that, almost without exception, they falled to achieve their goals for one or more of the following reasons. Often, printed materials and audiovisuals were found to be transparently biased, a feature which makes readers suspicious and unreceptive. Many others were overly technical, poorly written or unattractively designed-all qualities which reduce their educational effectiveness. As a result of the review, it was clear that the materials developed for this public education program had to be factual, simply written, and visually appealing. These findings were corroborated by the comments of the emergency planners who were interviewed: objective, easy-10-understand materials were desperately needed.

In the second slage of the planning process two targe audiences for the program were identified. Emergency planning officials at the regional, state and local levels comprise the first level target audience. In this way, the public education materials will be available for distribution to the second level audience-members of the general public who live within 50 miles of nuclear power plants. Within the general public, certain groups with special requirements for informa. tion have been identified: people in higher risk categories (pregnant women and children); health, police, and fire personnel; and schoof officials, teachers, and elementary and high school students.

In order for people in these groups to acquire a basic understanding of the dual issues of nuclear power and radiation, they need to be familiar with several distinct, yet interrelated subjects. Recognizing this, FEMA Identified several message areas which are central to the public education effort-and which will be treated in varying degrees of detail in each of the information program products. These message areas range from the basics of nuclear power plant operation and the health effects of radiation to safety precautions at nuclear power plants and the lessons of Three Mile Island.

To accommodate the differing needs, interests and backgrounds of specific segments within the target audiences. FEMA is producing a range of educational materials. some of which treat the message areas in detail (intended for people who request information of emergency planners or who have a need for in-depth explanations, such as teachers) and some of which treat the message areas in a simplified manner. (intended for mass distribution).

Quality education materials alone will not accomplish the objectives of the public awareness program, however. Success hinges on adequate preparation of state and local emergency planners in the use of the materials. To help assure that EPOs use the program materials effectively in their own community education efforts, FEMA is producing a public education resource handbook called "Getting Out the Facts." It is a practical, step-by-step guide through the public education process which explains everything from how to reach target audiences within the community to how to write a press release.

in addition, FEMA plans to conduct staff development sessions (tentatively scheduled in early 1982) for regional representatives and state EPOs at which they will receive special training in conducting local public awareness programs. The regional and state EPOs will also learn how to conduct similar staff development sessions for the local EPOS in their own states.

Distribution of the public education program materials will be done in three stages. At the staff development sessions FEMA will distribute to each regional and state EPO a special "Nuclear Power and Radiation: A Matter of Fact" box, containing the printed materials and a copy of the public education resource handbook. The box is designed to hold the audiovisual products which will be produced in FY 1982. including: a $16 \mathrm{~mm}$. 20-minute color film for general audiences (which will also be available in videocassette) and an accompanying guide that will summarize its content. provide advice on how to use it, and suggest follow-up activities; a fiveminute. Super $8 \mathrm{~mm}$ version of the same film; -a five-minute, $16 \mathrm{~mm}$ "trigger" film for use as a discussion starter; and taped public service announcements.

Subsequently, each of the 10,000 local EPOs around the country will receive a catalog/order form announcing the start of the campaign and giving them the opportunity to order the information materials, the audiovisuals (when completed), and bulk copies of each of the printed materials. Local emergency planners will then distribute these materials to residents in their communities.

The nuclear energy debate is too important to be dismissed as too complicated or to be accepted with complacency. The issues and the technology are complex, but they are not incomprehensible. It is possible for someone who is not an expert to understand the work. ings of a nuclear power plant and to grasp the intricacies of radiation. The purpose of FEMA's nuclear power and radiation awareness program is to assist the public in comprehending the information available to them.

-David Cobb

\section{FIREFIGHTERS' MEMORIAL DEDICATED AT FEMA'S NATIONAL EMERGENCY TRAINING CENTER}

A Firefighters' Memorial, honoring firefighters who have died in the line of duty, was dedicated at FEMA's National Emergency Training Center campus in Emmitsburg. Md.. on October 4, 1981.

The memorial honors the estimated 160 firefighters who die annually safeguarding American lives. Another 100,000 firefighters are injured each year in the line of duty.

President Reagan sent a special message for the dedication ceremony and was formally represented by Senator Ted Stevens

(R-Alaska), majority whip in the United States Senate. Also speaking at the event were Congressman Doug Walgren (D-Pennsylvania), Chairman of the House Subcommittee on Science. Research, and Technology, and Maryland Governor Harry Hughes. About 1,200 people attended the ceremony.

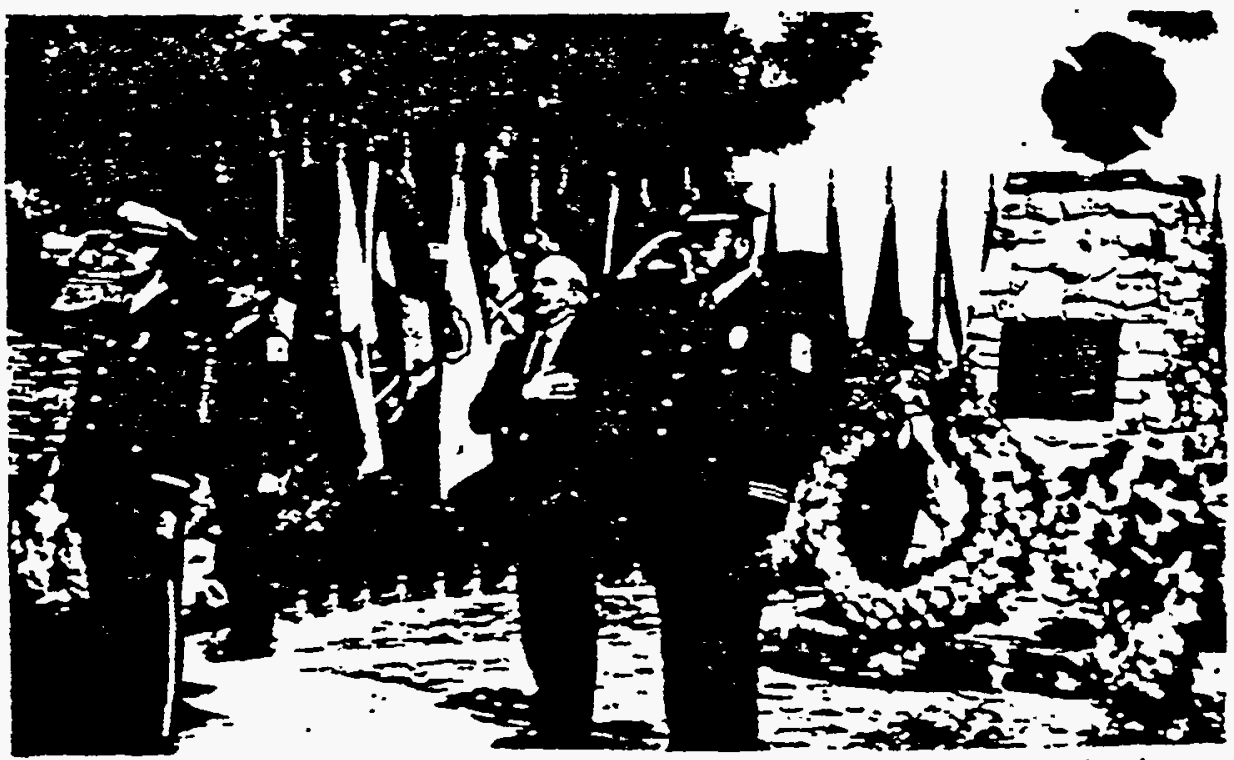

NATIONAL FIRE A CADEMY ACTING SUPERINTENDANT ED WALL, Ranked by National Fire Service Honor Guard, pays

mibute to the mation's forefighters during the tribute to the nation's fof ghters durite dedication ceremonies of a mational Fire.
fighters' Memorial in Emmitsburs. Maryland

$c-\dot{x} \dot{c}$ 